\title{
Patterns of sperm usage in large house spiders (Tegenaria spp.): genetics of esterase markers
}

\author{
G. S. OXFORD \\ Department of Biology, University of York, York Y01 5DD, U.K.
}

\begin{abstract}
Wild-mated, female large house spiders (Tegenaria gigantea and T. saeva) and their offspring were analysed by polyacrylamide gel electrophoresis in order to establish the genetic control of esterase isozyme markers. Three esterase systems (groups of bands) are recognized. Bands of systems I and III are inherited in a co-dominant fashion and are controlled by two autosomal loci. Bands of system II are inherited in a more complex way which is not yet fully resolved. All loci controlling esterases are very tightly linked forming what is operationally a single esterase 'locus' at which there are potentially 90 composite 'alleles'. At least one wild-caught female had mated more than once and analysis of her broods suggests that sperm from different males may mix uniformly prior to the fertilization of eggs. This conclusion needs to be substantiated using experimental matings.
\end{abstract}

Keywords: arachnids, electrophoresis, esterases, sperm priority, spiders, Tegenaria.

\section{Introduction}

There is currently much interest in determining the occurrence and patterns of sperm precedence in animals (e.g. Birkhead \& Hunter, 1990, and references therein). When a female mates with more than one male, sperm from different partners may mix in the female's reproductive tract so that the paternities of her offspring merely reflect the quantities of sperm passed by each male (a 'raffle' system: Parker, 1984, 1990). In many cases, however, sperm from the first or the last male has priority and fertilizes a disproportionate number of eggs. Whichever of these situations prevails, the particular pattern of sperm usage by a female is an important determinant of peri-reproductive behaviour (Parker, 1970, 1984). An understanding of sperm precedence patterns can therefore help in the interpretation of otherwise puzzling male behaviours such as preand post-copulatory guarding of females and multiple copulations with the same mate.

Much of the work on sperm precedence patterns has involved insects (e.g. Parker, 1970, 1984; Gwynne, 1984; Rubenstein, 1989; Birkhead \& Hunter, 1990), although a number of vertebrates have also been examined (e.g. Foltz \& Schwagmeyer, 1989; Schwartz et al., 1989; Møller \& Birkhead, 1989; Birkhead \& Hunter, 1990). In this context, spiders have been rela- tively neglected, although they would seem to be an ideal group for an integrated study of sperm usage and the behaviour patterns resulting from it. Female spiders often mate with several males and their peri-reproductive behaviour frequently takes place on webs which are easy to find, mark and monitor.

To the author's knowledge, sperm precedence in spiders has been examined in only five species from three families. In studies of three species the sterile male technique was used, where virgin females are double mated with fertile and radiation-sterilized individuals (Austad, 1982; Christensen, 1987, 1990; Jackson, 1980; Vollrath, 1980). The pattern of sperm usage is assessed by counting the proportion of viable embryos in one or more egg sacs when the sterile male is the first or the last to mate, and comparing this with fertile/fertile and sterile/sterile male controls (Austad, 1984). A major disadvantage of this technique is that patterns of multiple matings and sperm usage cannot be sought in natural populations. The use of visible genetic markers to investigate sperm precedence has not been applied to spiders, although in some species appropriate variation is present, e.g. Enoplognatha ovata (Oxford, 1983). This method also has its drawbacks. For example, simply inherited, visible variation is often not present in species of interest, dominance complicates analyses of broods, and the number of 
morphs is usually very limited, a problem when wildmated individuals are to be studied, and the morphs themselves could influence mating patterns.

A third technique, widely used in other organisms, is to follow the fate of sperm with allozyme markers, a method that suffers from none of the problems mentioned above. This approach has been used in studies of two species of spider (Martyniuk \& Jaenike, 1982; Watson, 1990). To encompass a sufficient level of genetic variability, allelic variation at a number of different enzyme-coding loci might have to be assayed. Alternatives would be to use a one hypervariable system, for example genetic fingerprinting (Burke, 1989 ), or to identify highly complex isozymes which can be scored on a single gel.

In this report, the genetics of non-specific esterases in two very closely related species of large house spider, Tegenaria gigantea Chamberlin \& Ivie and $T$. saeva Blackwall is described. The complexity of this system, resulting from a wealth of variation within loci and very tight linkage between them, means that it provides an ideal marker for investigating sperm priority patterns in a family of spiders (Agelenidae) previously unstudied from this point of view. Preliminary data on how females use sperm are also presented.

\section{Materials and methods}

Mature, wild-mated females of both species were collected in and around York during winter 1988/89 and isolated in 4-1 plastic jars containing paper tissue and a plastic-mesh support for web building. Each spider was fed one blowfly (Calliphora spp.), and the jar was sprayed with water, once a week. Cocoons were collected, attached to paper towelling and placed in individual glass jars (capacity $\sim 0.5 \mathrm{l}$ ) containing a piece of paper tissue. The tissue was dampened approximately twice a week and once young had emerged they were fed on Drosophila melanogaster at the same time. Young emerged from cocoons after approximately 4 weeks and had grown to a size at which all esterases were fully expressed after a further 4 weeks. All spiders were maintained at room temperature $\left(22-25^{\circ} \mathrm{C}\right)$ under a $17 \mathrm{~L}: 7 \mathrm{D}$ photoperiod.

Young spiders were killed at $-20^{\circ} \mathrm{C}$ and homogenized whole with a rotating glass rod in an equal volume of reservoir buffer. Female parents were killed likewise and homogenized whole but in approximately 2 volumes of buffer and the crude extract spun down in a micro-centrifuge at $4^{\circ} \mathrm{C}$. All extracts were stored at $-20^{\circ} \mathrm{C}$. Polyacrylamide gel electrophoresis of these crude extracts was carried out as described by Oxford (1986). Gels were run for $2 \mathrm{~h} 10 \mathrm{~min}$ at a constant $250 \mathrm{~V}$, and subsequently stained for non-specific ester- ases in a sodium citrate/citric acid buffer $(\mathrm{pH} 5.2)$ using $\alpha$ - and $\beta$-naphthyl acetates as substrates and Fast Garnet $\mathrm{GBC}$ as stain. Gels were fixed and stored in 50 per cent ethanol at $4^{\circ} \mathrm{C}$.

\section{Results}

In terms of gross esterase patterns, Tegenaria saeva and $T$. gigantea were found to be identical. Relatively few unrelated animals were examined, however, and the species may differ in the numbers of alleles and in their frequencies. A typical banding pattern revealed after electrophoresis is shown in Fig. 1. It is convenient to divide the gel into three regions, designated I, II and III, since these seem to correspond to separate genetic systems.

Systems I and III are relatively simple to interpret. In III, the three electromorphs are termed fast $(\mathrm{F})$, medium $(\mathrm{M})$ and slow $(\mathrm{S})$ according to relative electrophoretic mobilities (Fig. 1). The M band runs to a position equidistant between $\mathrm{F}$ and $\mathrm{S}$. Two fainter staining sub-bands anodal to the main zones are present in all phenotypes. The spacing of these sub-bands is identical to that of the primary products and they probably represent post-translational derivatives. The relative

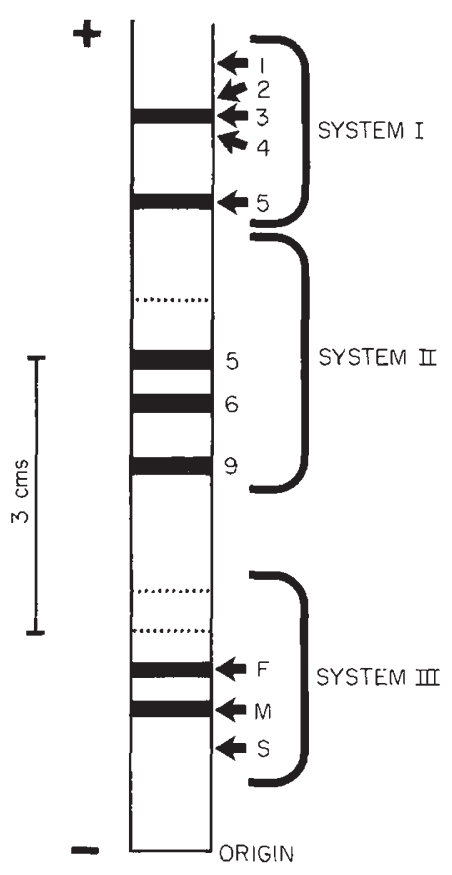

Fig. 1 Schematic diagram of a typical esterase profile showing the relative dispositions of systems I, II and III. The composite phenotype of this individual is $3 / 5, \mathrm{C}, \mathrm{F} / \mathrm{M}$. Within systems I and III the positions to which allozymes migrate are indicated by arrows; details of variation in system II are given in Fig. 2. Dotted zones are fainter staining. 
staining intensities of primary zones and sub-bands are such that genotypes can be unequivocally scored. The pattern of variation is consistent with a model of three co-dominant alleles at one autosomal locus (Table 1). The putative SS genotype was not observed. Genotypes, and their proportions, in the progeny of $\mathrm{SJH} 3$ were not consistent with a single-pair mating and suggest the female had mated more than once. Numbers of genotypes FM and FS were too small to allow the calculation of a heterogeneity chi-square value, but one or both were represented in all broods and showed no trends in frequency with brood order. For mating BY, the female parent was repeatedly scored as FF yet her offspring fell into a good 1:2:1 ratio of FF:FM:MM. The reason for this is not clear.

Electromorphs of system I also segregate in a manner suggesting control by alleles at a single autosomal locus (Fig. 1, Table 2). Five alleles are recognized and are numbered from anode to cathode. All 15 of the possible genotypes were observed. Sub-banding was present in some cases and sometimes caused difficulties in scoring. In two instances, the number and/or ratio of genotypes did not conform to expectation on the assumption of a single-pair mating. Broods of SJH3 showed five genotypes with a requirement for at least three different paternal alleles, namely 1,3 and 5 . There was no heterogeneity in genotype frequencies among broods. Broods of $\mathrm{T} 1$ were heterogeneous with respect to proportions of $3 / 3$ and $1 / 3$ and the ratios overall differed from $1: 1$.

The inheritance of system II zones is much more complicated. In the present data, 12 patterns of electromorphs are recognized (Fig. 2), designated A through $\mathrm{M}$ ( $\mathrm{I}$ is omitted to prevent confusion with system I). All patterns observed to date can be constructed with various combinations of six banding sets, namely $1+3,2+4,5,5+7,6+9$ and 8 (or $5+8$ ) (Fig. 2). Sometimes these banding sets are simply superimposed, e.g. in broods of RAY, but in a number of cases they are not. For example, the ratio of phenotypes in broods of $\mathrm{HH}$ differ significantly from 1:1 but fit a 3:1 ratio very closely (Table 3 ). Similarly, the mother of the IMP broods possessed the D pattern yet produced offspring all with pattern $\mathrm{C}$.

Table 1 Segregation of electromorphs in system III

\begin{tabular}{|c|c|c|c|c|c|c|c|c|c|c|}
\hline \multirow[b]{2}{*}{ Code } & \multirow[b]{2}{*}{ QPar } & \multirow[b]{2}{*}{ Broods } & \multicolumn{5}{|c|}{ Progeny phenotypes } & \multirow[b]{2}{*}{ Total } & \multirow[b]{2}{*}{ Mend. } & \multirow[b]{2}{*}{ Heter. } \\
\hline & & & FF & FM & FS & MM & MS & & & \\
\hline CA1 & MM & 5 & - & - & - & 127 & - & 127 & - & - \\
\hline $\mathrm{CA} 2$ & MM & 7 & - & - & - & 258 & - & 258 & - & - \\
\hline $\mathrm{CA} 3$ & $\mathrm{MM}$ & 6 & - & - & - & 38 & 42 & 80 & $n s^{\mathrm{a}}$ & ns \\
\hline CA5 & MM & 3 & - & - & - & 56 & - & 56 & - & - \\
\hline CLE & FM & 5 & - & 93 & - & 94 & - & 187 & $\mathrm{~ns}^{\mathrm{a}}$ & ns \\
\hline $\mathrm{HH}^{\mathrm{G}}$ & MM & 3 & - & 42 & - & 39 & - & 81 & $\mathrm{~ns}^{\mathrm{a}}$ & ns \\
\hline $\mathrm{HV}$ & $?$ & 2 & 11 & 22 & - & 11 & - & 44 & $n s^{b}$ & ns \\
\hline IMP & $\mathrm{MM}$ & 5 & - & - & - & 174 & - & 174 & - & - \\
\hline $\mathrm{RAY}^{\mathrm{G}}$ & $\mathrm{MM}$ & 5 & - & - & - & 130 & - & 130 & - & - \\
\hline SAND & $\mathrm{MM}$ & 4 & - & - & - & 64 & - & 64 & - & - \\
\hline SJH1 & $\mathrm{MM}$ & 5 & - & 121 & - & 107 & - & 228 & $\mathrm{~ns}^{\mathrm{a}}$ & ns \\
\hline SJH3 & MS & 5 & - & 6 & 11 & 55 & 64 & 136 & $?$ & $?$ \\
\hline $\mathrm{WIL}^{\mathrm{G}}$ & FM & 7 & - & 113 & - & 95 & - & 208 & $n s^{\mathrm{a}}$ & ns \\
\hline $\mathrm{BX}$ & MM & 3 & - & - & - & 82 & - & 82 & - & - \\
\hline $\mathrm{BY}$ & FF? & 2 & 19 & 32 & - & 14 & - & 65 & $n s^{b}$ & ns \\
\hline DAV & $?$ & 3 & - & - & - & 167 & - & 167 & - & - \\
\hline $\mathrm{T} 1$ & $?$ & 6 & - & - & - & 263 & - & 263 & - & - \\
\hline
\end{tabular}

Code: females with the same letter code but different numbers derived from the same population (house). Superscript $G$ denotes Tegenaria gigantea, the rest are $T$. saeva.

OPar: Phenotype of female parent. ? parent died before scoring.

Broods: Number of separate broods analysed for all systems.

Mend. Probability associated with a $\chi^{2}$ test against Mendelian ratios. Superscripts denote the ratio tested; $a=1: 1, b=1: 2: 1$.

Heter. Probability associated with a $\chi^{2}$ test for heterogeneity among broods based on assumed Mendelian ratios. 
Table 2 Segregation of electromorphs in system I

\section{Progeny phenotypes}

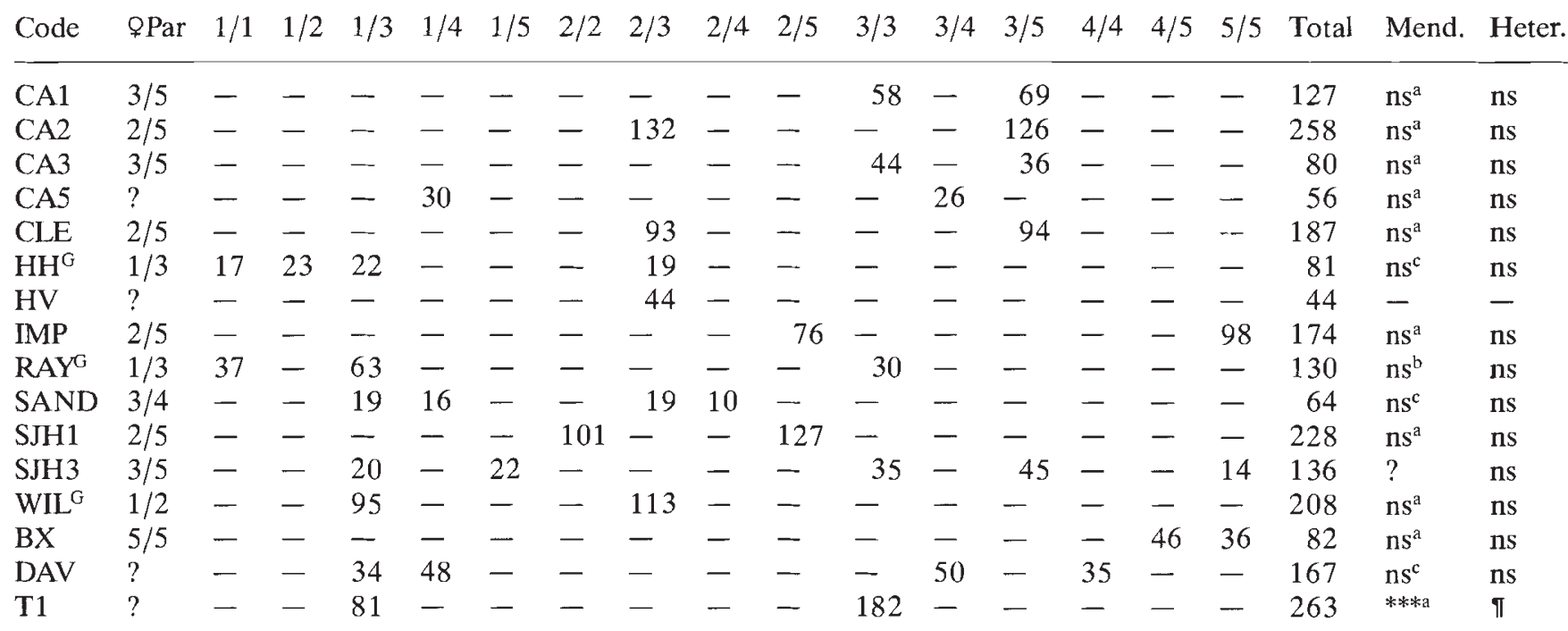

Column headings as in Table 1.

Mend. As in Table 1. Superscript $\mathrm{c}$ denotes a test against a 1:1:1:1 ratio. ?, no simple Mendelian ratio.

Heter. As in Table 1. For SJH3 and T1 the probability is based on an $\mathrm{r} \times \mathrm{c}$ contingency $\chi^{2}$ test.

*** $P<0.001$

$\pi 0.02>P>0.01$.

Phenotype of $\$$ Par CA5 was too faint to score reliably. Broods of BY could not be scored for this system.

Esterase systems I, II and III are all highly variable and if the loci controlling them are unlinked a large number of combinational phenotypes would be expected to segregate in broods. This was not found. Broods from individual females possessed only two or four phenotypic combinations. The one exception, with eight phenotypes, is $\mathrm{SJH} 3$, for which there is evidence for multiple paternity. The small number of gel patterns within broods suggests very tight linkage between all esterase loci. Indeed, no recombinants were observed among 2176 offspring in broods in which at least two systems were polymorphic. Deduced chromosome combinations in female and (unseen) male parents and their offspring are shown in Table 4. The existence of three highly polymorphic systems, with tight linkage between the loci controlling them, means that the esterases of Tegenaria gigantea and $T$. saeva are determined by what is operationally a single hypervariable locus.

\section{Discussion}

Esterase electromorphs in systems I and III are simply determined by co-dominant alleles at two different loci.

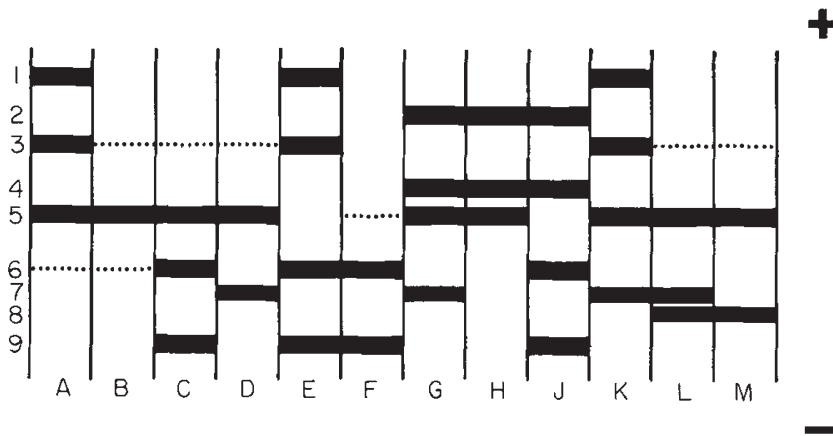

Fig. 2 Schematic diagram showing the suite of phenotypes observed in system II. Dotted lines indicate faintly staining zones which may or may not be identical to strongly staining electromorphs.

Patterns in system II present some interesting features, for example, pairs of bands which always segregate together. One of the bands may represent a post-translational modification of the other, a possibility supported by the uniform spacing within the four bandpairs. The 3:1 ratio in broods of $\mathrm{HH}$ suggests either a null allele or some form of dominant modification. 
Table 3 Segregation of electromorphs in system II

\begin{tabular}{|c|c|c|c|c|c|c|c|c|c|c|c|c|c|c|}
\hline \multirow[b]{2}{*}{ Code } & \multirow[b]{2}{*}{ OPar } & \multicolumn{10}{|c|}{ Progeny phenotypes } & \multirow[b]{2}{*}{ Total } & \multirow[b]{2}{*}{ Mend. } & \multirow[b]{2}{*}{ Heter } \\
\hline & & A & B & $\mathrm{C}$ & $\mathrm{D}$ & $\mathrm{E}$ & $F$ & G & $\mathrm{H}$ & $\mathrm{J}$ & $\mathrm{L}$ & & & \\
\hline CA1 & $\mathrm{C}$ & - & - & 69 & 58 & - & - & - & - & - & - & 127 & $\mathrm{~ns}^{\mathrm{a}}$ & ns \\
\hline $\mathrm{CA} 2$ & $\mathrm{C}$ & _- & - & 126 & 132 & - & - & - & - & - & - & 258 & $\mathrm{~ns}^{\mathrm{a}}$ & ns \\
\hline $\mathrm{CA} 3$ & $\mathrm{C}$ & - & 23 & 15 & - & - & - & - & 21 & 21 & - & 80 & $n s^{c}$ & ns \\
\hline CA5 & $\mathbf{M}$ & - & - & - & 26 & - & - & - & - & - & 30 & 56 & $\mathrm{~ns}^{\mathrm{a}}$ & ns \\
\hline CLE & $\mathrm{D}$ & - & 93 & - & 94 & - & - & - & - & - & - & 187 & $\mathrm{~ns}^{\mathrm{a}}$ & ns \\
\hline \multirow[t]{2}{*}{$\mathrm{HH}^{\mathrm{G}}$} & $\mathrm{D}$ & - & 19 & - & 62 & - & - & - & - & - & - & 81 & $* * * a$ & ns \\
\hline & & & & & & & & & & & & & $n s^{\mathrm{d}}$ & ns \\
\hline $\mathrm{HV}$ & ? & - & 19 & - & 25 & - & - & - & - & - & - & 44 & $\mathrm{~ns}^{\mathrm{a}}$ & ns \\
\hline IMP & $\mathrm{D}$ & - & - & 174 & - & - & - & - & - & - & - & 174 & - & - \\
\hline RAYG & $\mathrm{C}$ & - & 30 & 63 & - & - & 37 & - & - & - & - & 130 & $\mathrm{~ns}^{\mathrm{b}}$ & ns \\
\hline SAND & K & 19 & - & - & 26 & 19 & - & - & - & - & - & 64 & $\mathrm{~ns}^{\mathrm{b}}$ & ns \\
\hline SJH1 & D & - & 101 & - & 127 & - & - & - & - & - & - & 228 & $\mathrm{~ns}^{\mathrm{a}}$ & ns \\
\hline SJH3 & G & - & - & - & 61 & - & - & 40 & 35 & - & - & 136 & $n \mathbf{s}^{\mathrm{b}}$ & ns \\
\hline WIL $^{G}$ & $\mathrm{C}$ & - & 113 & 95 & - & - & - & - & - & - & - & 208 & $\mathrm{~ns}^{\mathrm{a}}$ & ns \\
\hline BX & $\mathrm{C}$ & - & - & 82 & - & - & - & - & - & - & - & 82 & - & - \\
\hline BY & B & 34 & 31 & - & - & - & - & - & - & - & - & 65 & $n \mathrm{~s}^{\mathrm{a}}$ & ns \\
\hline DAV & $?$ & - & 85 & 82 & - & - & - & - & - & - & - & 167 & $n s^{\mathrm{a}}$ & ns \\
\hline $\mathrm{T} 1$ & $?$ & - & 182 & 81 & - & - & - & - & - & - & - & 263 & $* * * a$ & $\pi$ \\
\hline
\end{tabular}

Column headings as in Table 1.

Mend. As in Table 1. Superscripts $c$ and d denote tests against ratios 1:1:1:1 and 3:1, respectively.

Heter. For T1 the probability is based on an $\mathbf{r} \times \mathrm{c}$ contingency $\chi^{2}$ test.

Note. Phenotypes in broods of $\mathrm{SJH} 3$ do not differ significantly from a 1:2:1 ratio. This is probably a coincidence given the evidence for multiple mating (see text).

*** $P<0.001$.

$\pi 0.05>P>0.02$.

However many loci are concerned, all are clearly linked to those determining system I and III zones. Further speculation regarding the genetic relationship of elements comprising system II is not worthwhile until broods for which both parents are known are analysed. The important point is that patterns clearly are inherited. Given the number of alleles observed in systems I and III, and the number of banding sets in system II, the esterase 'locus' has the potential to produce 90 composite 'alleles', and is therefore an ideal genetic marker for sperm usage studies. The number of 'alleles' present in a single population will, of course, be much lower than this.

Of the 17 matings considered here two, T1 and $\mathrm{SJH} 3$, show esterase patterns segregating in the progeny which are not in simple Mendelian ratios. For T1, there is significant heterogeneity among broods in the proportions of the two composite phenotypes and they differ significantly from a 1:1 ratio overall. The reasons for this are not clear. There are no trends in pattern frequencies among successive broods and since all progeny were raised under identical conditions, inter- brood variation in the viability of specific genotypes is also unlikely.

Broods of $\mathrm{SJH} 3$ produced compelling evidence that the female had mated with two males. The ratios of phenotypes in successive broods suggest that sperm from the males thoroughly mixed prior to the first batch of eggs being fertilized. Thus, the proportion of offspring carrying allele 1 (system I), which must have come from one of the male parents, in broods $1,3,4,5$ and 6 was 0.30 (brood size, $n=40), 0.19(n=21), 0.47$ $(n=15), 0.31(n=29)$ and $0.32(n=22)$, respectively. These proportions are statistically homogeneous $\left(x_{(4)}^{2}=3.161\right.$, ns). If substantiated, this situation of sperm mixing contrasts with that in other spiders where sperm from the first male seems to have priority (Austad, 1984). However, Brown (1985) noted that whether sperm priority is found or not might depend on the interval between successive matings and the time required for sperm capacitation. If the former is short compared with the latter, sperm priority may not occur. Whether sperm mixing is peculiar to Tegenaria saeva (and T. gigantea?) or whether it is a general 
Table 4 Composite esterase phenotypes of offspring and inferred chromosome complements of parents

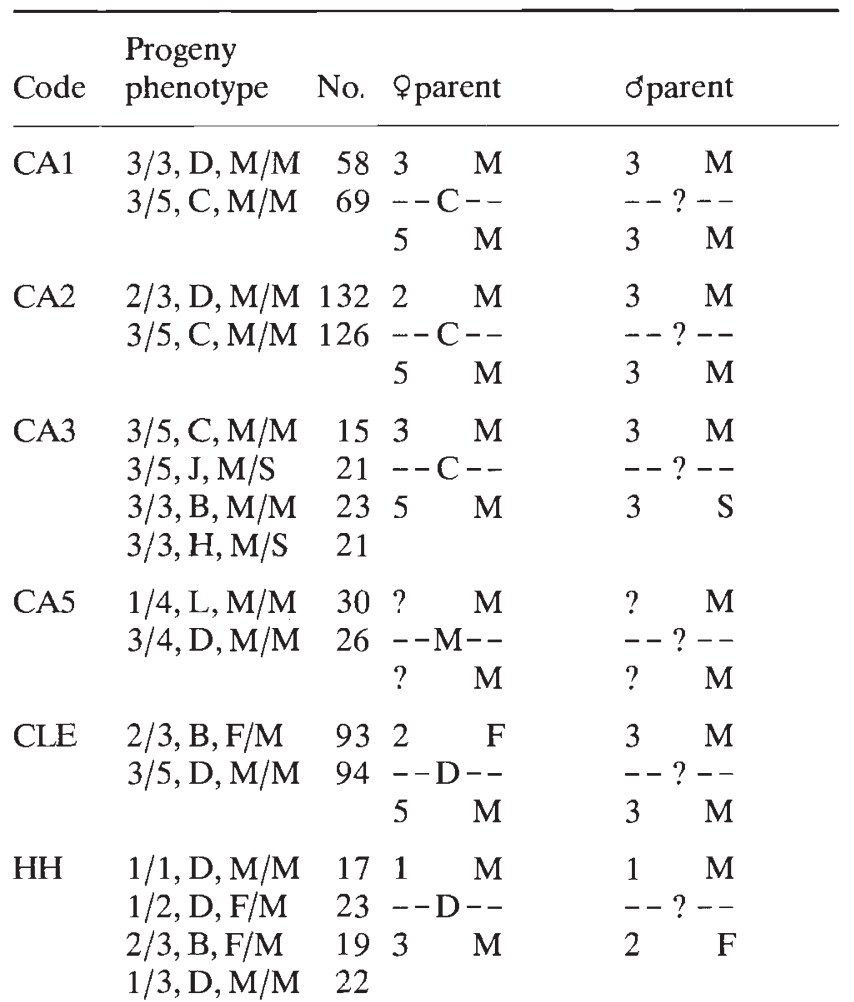

HV $2 / 3, \mathrm{~B}, \mathrm{~F} / \mathrm{F} \quad 11$ Female died before analysis

$2 / 3, \mathrm{~B}, \mathrm{~F} / \mathrm{M} \quad 8$

$2 / 3, \mathrm{D}, \mathrm{M} / \mathrm{M} \quad 11$

2/3, D, F/M 14

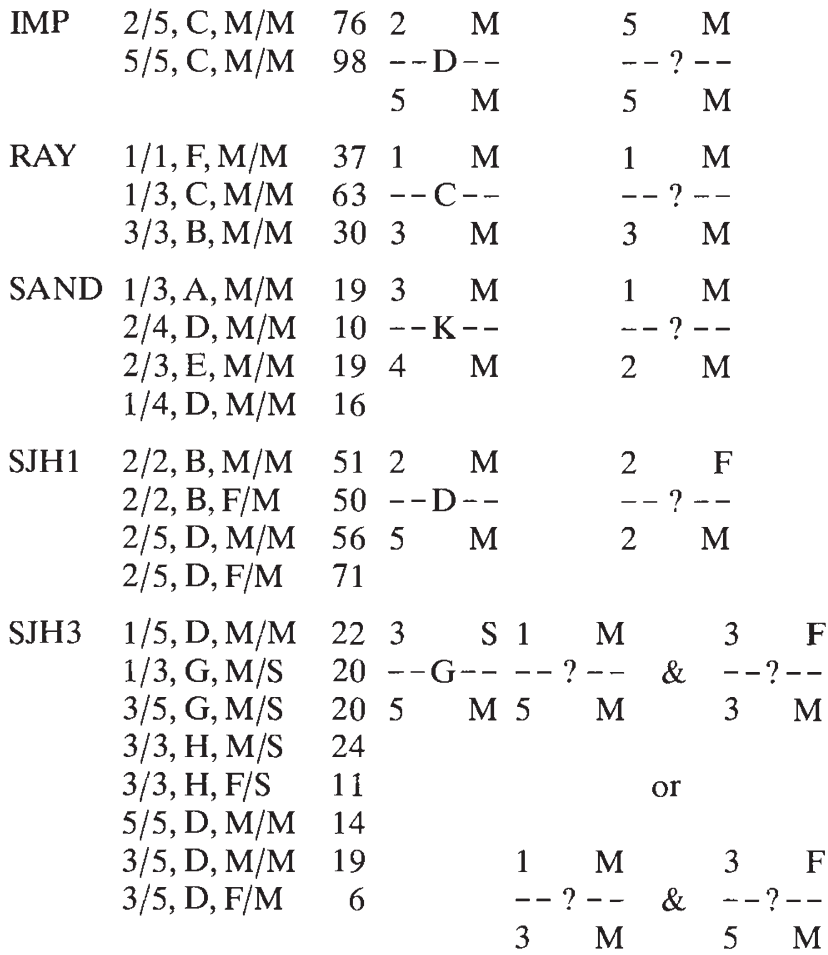

Table 4 Continued

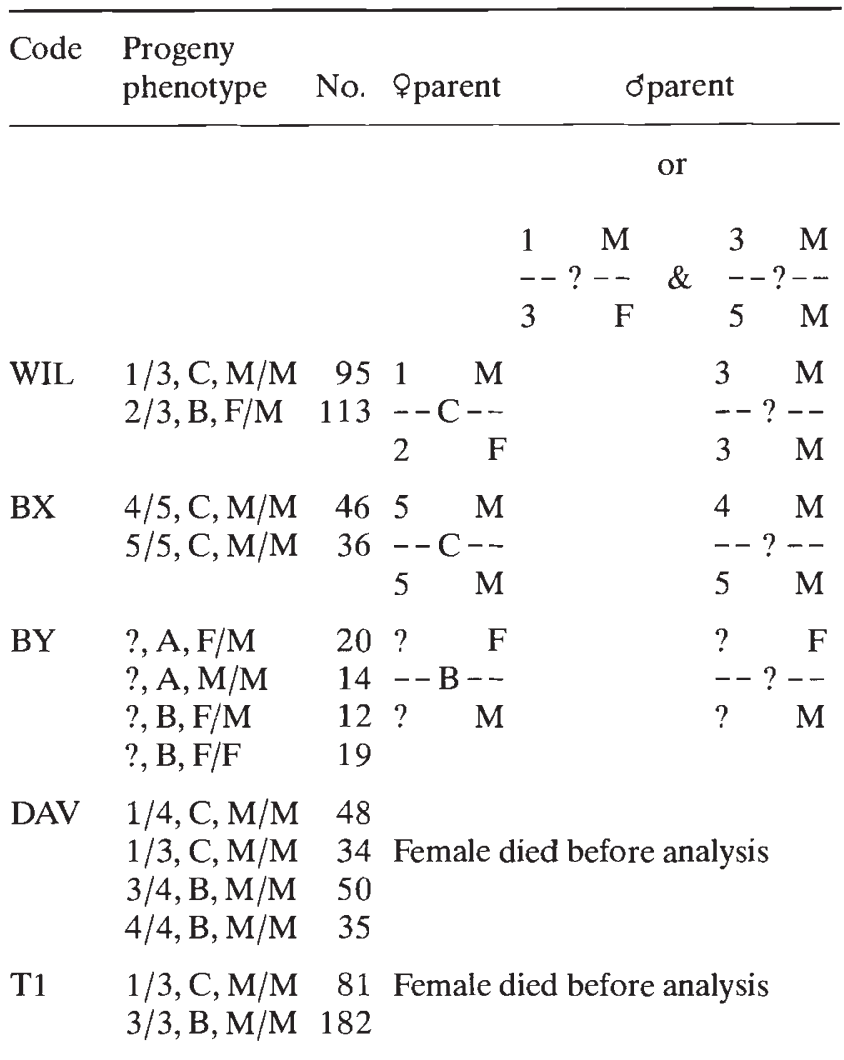

Progeny phenotypes are given in the order system I, II, III. Parental chromosome complements assume the same order although there is no evidence that this is correct.

The non-additivity in system II precludes allelic designation and maternal phenotypes are shown.

Most phenotypic proportions do not differ significantly from $1: 1,1: 1: 1: 1$ or $1: 2: 1$ ratios, as appropriate. The two exceptions are T1 and SJH3. For the latter, contributions from each male should produce phenotypes that fall into a 1:1:1:1 ratio. Whichever combination of males is considered, one of the two ratios differ significantly from expectation; for the first combination contributions from $\sigma^{1} 1, \chi_{(3)}^{2}=1.89$ (ns) and from $\sigma^{2} 2, \chi_{(3)}^{2}=12.93(0.01>P>0.001)$, for the second combination contributions from $\sigma^{1} 1, \chi_{(3)}^{2}=0.69(\mathrm{~ns})$ and from $\sigma^{\prime} 2, \chi_{(3)}^{2}=8.06(0.05>P>0.02)$, and for the third combination, from $\sigma^{1} 1, \chi_{(3)}^{2}=2.64$ (ns) and from $\sigma^{2} 2$, $\chi_{(3)}^{2}=11.58(0.01>P>0.001)$. 
characteristic of the family Agelenidae remains to be seen. The apparent incidence of multiple matings by the females studied here may be an underestimate. To be detected, successive males must differ in their esterase phenotypes; the extent to which this is likely in small, predominantly house-bound populations is unknown. Work is now in progress to investigate experimentally patterns of sperm priority and sperm usage in these species.

\section{Acknowledgements}

I would like to thank colleagues who supplied spiders for this study, and Terry Crawford and Paul Yoward for comments on the manuscript.

\section{References}

AUSTAD, S. N. 1982. First male sperm priority in the bowl and doily spider (Frontinella pyramitela). Evolution, 25, 777-785.

AUSTAD, S. N. 1984. Evolution of sperm priority patterns in spiders. In: Smith, R. L. (ed.) Sperm Competition and the Evolution of Animal Mating Systems, Academic Press, London, pp. 223-249.

BIRKHEAD, T. R. AND HUNTER, F. M. 1990. Mechanisms of sperm competition. Trends Ecol. Evol., 5, 48-52.

BROWN, S. G. 1985. Mating behavior of the Golden-OrbWeaving spider, Nephila clavipes: II. Sperm capacitation, sperm competition and fecundity. J. Comp. Psychol., 99, 167-175.

BURKE, T. 1989. DNA fingerprinting and other methods for the study of mating success. Trends. Ecol. Evol., 4, 139-144.

CHRISTENSON, T. E. 1987. X-ray sterilisation of male goldenweb spiders, Nephila clavipes. J. Arachnol., 14, 401-403.

CHRISTENSON, T. E. 1990. Natural selection and reproduction: A study of the golden orb-weaving spider. In: Dewsbury, D. A. (ed.) Contemporary Issues in Comparative Psychology, Sinauer Associates Inc., Sunderland, Massachusetts, pp. 149-179.
FOLTZ, D. W. AND SCHWAGMEYER, P. L. 1989. Sperm competition in the thirteen-lined ground squirrel: differential fertilization success under field conditions. Am. Nat., 113, 257-265.

GWYNNE, D. T. 1984. Male mating effort, confidence in paternity, and insect sperm competition. In: Smith, R. L. (ed.) Sperm Competition and the Evolution of Animal Mating Systems, Academic Press, London, pp. 117-149.

JACKSON, R. R. 1980. The mating strategy of Phidippus johnsoni (Araneae: Salticidae): II. Sperm competition and the function of copulation. J. arachnol., 8, 217-240.

MARTYNIUK, J. AND JAENIKE, J. 1982. Multiple mating and sperm usage patterns in natural populations of Prolinyphia marginata (Araneae: Linyphiidae). Ann. Ent. Soc. Am., 75, 516-518.

MølleR, A. P. AND BIRKHEAD, T. R. 1989. Copulatory behaviour in mammals: evidence that sperm competition is widespread. Biol. J. Linn. Soc., 38, 119-131.

OXFORD, G. S. 1983. Genetics of colour and its regulation during development in the spider Enoplognatha ovata (Clerck) (Araneae: Theridiidae). Heredity, 51, 621-634.

OXFORD, G. S. 1986. Multiple amylase loci in Asellus (Crustacae: Isopoda): Genetics and linkage. Heredity, 56, $105-110$

PARKER, G. A. 1970. Sperm competition and its evolutionary consequences in the insects. Biol. Rev., 45, 525-567.

PARKER, G. A. 1984. Sperm competition and the evolution of animal mating strategies. In: Smith, R. L. (ed.) Sperm Competition and the Evolution of Animal Mating Systems, Academic Press, London, pp. 2-60.

PARKER, G. A. 1990. Sperm competition games: Raffles and roles. Proc. Roy. Soc. London. B, 242, 120-126.

RUBENSTEIN, D. T. 1989. Sperm competition in the water strider, Gerris remigis. Anim. Behav., 38, 631-636.

SCHWARTZ, J. M., MCCRACKEN, G. F. AND BURGHARDT, G. M. 1989. Multiple paternity in wild populations of the garter snake. Thamnophis sirtalis. Behav. Ecol. Sociobiol., 25, 269-273.

VOLlRATH, F. 1980. Male body size and fitness in the webbuilding spider Nephila clavipes. Z. Tierpsychol., 53, 61-78.

WATSON, P. J. 1990. Female-enhanced male competition determines the first mate and principal sire in the spider Linyphia litigiosa (Linyphiidae). Behav. Ecol. Sociobiol., 26, 77-90. 